\title{
Article
}

\section{Transient Nanoscale Tribofilm Growth: Analytical Prediction and Measurement}

\author{
Michael Leighton ${ }^{1,2}$, Nick Morris ${ }^{1, * \mathbb{D}}$ and Homer Rahnejat 1,3 \\ 1 Wolfson School of Mechanical, Electrical and Manufacturing Engineering, Loughborough University, \\ Loughborough LE11 3TU, UK; Michael.Leighton@avl.com (M.L.); HRahnejat@uclan.ac.uk (H.R.) \\ 2 AVL List GmbH, 8020 Graz, Austria \\ 3 School of Engineering, University of Central Lancashire, Preston PR1 2HE, UK \\ * Correspondence: N.J.Morris@lboro.ac.uk
}

Citation: Leighton, M.; Morris, N.; Rahnejat, H. Transient Nanoscale Tribofilm Growth: Analytical Prediction and Measurement. Appl. Sci. 2021, 11, 5890. https://doi.org/ 10.3390/app11135890

Academic Editor:

Alessandro Ruggiero

Received: 15 April 2021

Accepted: 22 June 2021

Published: 24 June 2021

Publisher's Note: MDPI stays neutral with regard to jurisdictional claims in published maps and institutional affiliations.

Copyright: (C) 2021 by the authors. Licensee MDPI, Basel, Switzerland. This article is an open access article distributed under the terms and conditions of the Creative Commons Attribution (CC BY) license (https:// creativecommons.org/licenses/by/ $4.0 /)$.

\begin{abstract}
A new method for the simultaneous in situ measurement and characterisation of molybdenumbased tribofilms is presented, based on lateral force microscopy. The simultaneity of measurements is crucial for a fundamental understanding of the tribochemical phenomena. A new analytical method is also presented, which combines a BET multi-layer adsorption/desorption model for boundary-active lubricant species-surface combination with the modified shear-promoted thermal activation Arrhenius equation. Therefore, the expounded method integrates the mechanical, physical and chemical aspects of the adsorption-bonding process as a detailed multi-step phenomenon. The method provides detailed explanations of the measured tribofilm growth, in a fundamental manner, not hitherto reported in the literature. Therefore, the combined experimental methodology and modelling approach provides a significant advance in the understanding of tribofilm formation. Furthermore, the developed model has the potential to explain the behaviour of many complex lubricant formulations and the resulting multi-species tribofilms, generated through synergistic and/or antagonistic constituent adsorption and shear-promoted activation.
\end{abstract}

Keywords: tribofilm growth; lateral force microscopy; BET multi-layer adsorption model; Arrhenius equation

\section{Introduction}

Lubrication is crucial for the functional performance of a wide range of mechanical and biological interfaces. Most interfaces operate under a mixed regime of lubrication, meaning that a certain degree of direct interaction of stochastic solid contacting surfaces occurs. Therefore, the conditions endured by many interfaces require the formation of an intervening fluid film to extend beyond its mere bulk microscale rheology. Protective boundary-active additives are used to form surface-adhered/bonded tribofilms. These can contribute to a reduction in contact friction and prevent wear in the nanoscale interactions of surface asperities in mechanical as well as biological interfaces. Hitherto, despite significant improvements in lubricant technology, it is estimated that $23 \%$ of the world's total energy consumption is dissipated in tribological contacts [1].

Typically, additives form around 5-24 wt\% of fully formulated lubricants for engineering applications [2,3]. Depending on application, lubricants comprise a blend of hydrocarbon base stock, as well as detergents, dispersants, antioxidants, friction and viscosity modifiers, anti-foaming agents, pour point depressants, corrosion inhibitors and anti-wear additives [3]. In the formulation, the constituent physical chemistry enhances certain aspects of the lubricant system performance and can be adjusted to suit specific applications.

Despite their crucial intended functions, the mechanisms through which most additives adsorb or bond to surfaces remain somewhat empirical, particularly due to their potential synergistic as well as antagonistic competition in occupying attachment sites on 
boundary surfaces [4]. The lack of a fundamental understanding is exacerbated by the significant difficulty associated with taking in situ measurements of additives' activation and tribofilm characterisation.

Molybdenum-based additives were first patented in 1939 in the form of colloidal molybdenum disulphide $\left(\mathrm{MoS}_{2}\right)$ as an anti-wear and friction modifying additive [5]. The use of oil soluble molybdenum dialkyldithiophosphate (MoDDP) was reported in 1955 as an alternative to zinc dialkyldithiophosphate (ZDDP) which was already in use [6]. Other forms of oil soluble molybdenum-based friction modifiers have also been used commercially, including molybdenum dithiocarbamate (MoDTC). The reaction process that transforms an oil soluble molybdenum-based molecule into a functional friction-reducing layer of $\mathrm{MoS}_{2}$ is chemical and requires energy and suitable reactants for initiation.

The Arrhenius equation has long been applied in chemistry to model the rate-limiting step in a reaction process [7]. Through modifying the Arrhenius equation, found in the seminal works of Prandtl [8] and Eyring [9], the mechanical contribution to reaction rates can also be considered as an energy input. Tysoe [10] and Spikes [11] have recently provided detailed summaries of the evolution of these concepts and their application in tribology through tribochemistry or mechanochemisty.

The shear-induced thermal activation model has recently gained prominence following the work of Gosvami et al. [12] on in situ activation of ZDDP via scanning Atomic Force Microscopy (AFM). Using a range of contact pressures and temperatures, Gosvami et al. [12] recorded the change in surface height at intervals after scanning with an AFM tip over a surface submerged in a lubricant containing ZDDP. The tip was scanned parallel to the cantilever support in order to promote additive activation, and then operated in tapping mode over the scanned area and its surroundings to assess the formed tribofilm height. By evaluating the increased film height after intervals of time, they were able to determine an exponential film growth rate which they linked to an Arrhenius model using the generated contact pressure as the source of supplied mechanical energy.

Zhang and Spikes [13] investigated the formation of ZDDP tribofilm using a Mini Traction Machine (MTM) to provide the necessary input mechanical energy and interferometry to measure the tribofilm growth. They adjusted the slide-roll ratio and applied contact load, thus the resulting shear and contact pressure, respectively. They concluded that shear, not normal pressure should be used as the main source of supplied mechanical energy, also when using the Arrhenius equation as a predictive tool. Zhang and Spikes [13] used the Eyring's reaction path concept [14] to demonstrate that induced shear not only lowers the activation energy barrier for the chemical reaction of boundary active additives, but also increases the potential barrier for the reversal of the reaction. Adams et al. [15] showed that for the case of dimethyl disulfide on a copper substrate in Ultra-High Vacuum (UHV), a Surface Force Apparatus (SFA) can be used to activate the molecules through shear and bond them to the surface. They made full use of the UHV environment by employing angle-resolved X-ray Photoelectron Spectroscopy (XPS) to track the chemical composition of the surface following the SFA activated chemical reaction.

The Prandtl [8] and Eyring [9,14] models apply a force-distance term (work done: $F \Delta x$ ) as the mechanical input energy, whilst Gosvami et al. [12] used the pressure volume term $(p \Delta V)$ and Zhang and Spikes [13] used a shear stress-volume term $(\tau \Delta V)$. The pressure and shear stress terms effectively represent the characteristic forces applied in the contact, whilst the volume terms (referred to as the activation volume) are necessary to provide a dimensionless exponential term in the Arrhenius equation. Zhang and Spikes [13] and Tysoe [10] provided experimental evidence that shear stress is the most pertinent characteristic force expression for the mechanical contribution to activation. The activation volume can be considered for vertically orientated molecules to be the area of the surface occupied by the molecule multiplied by the activation length [11]. Previous studies have suggested that a molecular area between 20 and $400 \AA^{2}$ and an activation volume between 7.8 and $180 \AA^{3}$ are applicable for various molecules, including ZDDP, fatty acids and base polymers $[13,16-20]$. 
A number of studies have measured the rate of growth of tribofilms with both fully formulated and partially formulated lubricants [21-27]. These studies have shown that there is a slow initial growth period, followed by an increased growth rate and finally a steady state region with a minimal increase or decrease in tribofilm thickness with time. This is particularly noteworthy in the study of Gosvami et al. [12] who fitted a linear relationship to the initial growth stage and modelled the subsequent faster growth rate with the Arrhenius model. They noted a "limiting value", beyond which the growth appears to cease and some small patches of the tribofilm are removed from the edges of the scan area under extreme AFM contact loads $(600-1700 \mathrm{nN})$. An important point to note is that neither the slow initial growth rate nor the limiting value can be explained by the Arrhenius model alone.

Akchurin and Bosman [28] used the data from the experimental work of Gosvami et al. [12] and applied a simple wear term to explain the observed plateauing of the growth rate. This wear rate term was included with the Arrhenius growth model and showed good agreement with the experimental results, although the underlying physical nature of the wear mechanism was not discussed in any detail. Many papers [29-31] have shown that wear at the nanoscale does not follow the behaviour demonstrated at larger scales described by classical wear models [32]. Therefore, despite the agreement between the models presented for AFM (nanoscale) [28] and the tribometric activated film growth (microscale) [24], it is unlikely that the same wear mechanism would be dominant at both physical scales. This is particularly evident as the film height is not seen to reduce in AFM studies, where the rate of growth merely decreases, and the film height stabilises. This has been hypothesised to be as the result of combined stable growth and wear rates acting in concert [24].

AFM is well-suited to the investigation of activation of lubricant additives. However, its use in the simultaneous measurement of surface height and friction in Lateral Force Microscopy (LFM) has not hitherto been reported in the literature. Additionally, there are some gaps in the current understanding of film growth characteristics, particularly in relation to the initial and limiting film growth mechanisms. This paper presents an advance in the understanding of tribofilm growth through novel simultaneous in situ nanoscopic measurement of friction and film growth height. In addition, previously presented models are adopted and further developed in order to provide better predictions of the early stage tribofilm growth through the inclusion of an adsorption model. It is shown that the inclusion of an adsorption model provides for better prediction of early stage tribofilm growth. It explains the observed limiting maximum tribofilm thickness and allows for the inclusion of additive presence at the adsorption sites.

\section{Experimental Methodology}

The current investigation uses a Group III high viscosity base oil with a $0.5 \mathrm{wt} \%$ concentration (approximately equating to $500 \mathrm{ppm}$ ) of MoDTC. The concentration MoDTC used here guards against interruption in tribofilm growth on account of a limited supply of the additive. MoDTC is a typical engine oil additive for generation of low friction $\mathrm{MoS}_{2}$ films and provides anti-oxidation properties [33]. The $\mathrm{MoS}_{2}$ films are generally produced in tandem with ZDDP films for combined wear protection and low frictional performance where direct boundary interactions occur [34]. The base oil used here has been investigated in detail for its shear characteristics as well as for boundary interactions of this additive at microscale tribometry, using a s range of engineering surface materials [35]. The investigation considered the interaction of a reciprocating sliding tribometer, intended to replicate a piston ring to cylinder liner conjunction, with different lubricant-material combinations. These included Nickle-Silicon-carbide, Borided Steel and EN14 steel (for the sliding strip). These materials were tested for frictional losses with the use of base oil containing only a single friction modifier species. The base oil, without friction modifier, was also investigated in isolation using LFM to determine the Eyring shear stress of the lubricant. The substrates used in the current investigation are super-finished EN31 steel 
specimens with isotropic topography and roughness of approximately $0.05 \mu \mathrm{m}(\mathrm{Sa})$. These plates were washed in an ultrasonic bath with petroleum ether (40-60) for a period of $10 \mathrm{~min}$ and air dried prior to experimentation.

To determine a base line coefficient of friction for the test specimens, friction was measured in the absence of any lubricant for a range of AFM probe tip contact loads. Bruker DNP-10 twin-arm silicon nitride cantilever with a nominal tip radius of $20 \mathrm{~nm}$ was used for these measurements. In order to characterise the cantilever a "blind" calibration technique was employed in line with that proposed by Buenviaje et al. [36] using a TGF 11 monocrystalline silicon grating. Following the cantilever calibration, the tip geometry was determined by taking a topographical measurement of a TGT 1 silicon wafer surface with calibrated peaks. Off-line deconvolution of the topographical data enables the determination of tip geometry. The measured tip radii were within $1 \mathrm{~nm}$ of those specified by the manufacturer, when averaged over 20 peaks from the calibration sample's scanned area.

Measurements were taken from 3 areas of all the EN31 steel samples, with a new tip calibrated and used for each test. The steel sample was a $50 \mathrm{~mm} \times 20 \mathrm{~mm} \times 5 \mathrm{~mm}$ plate with two counter-sunk mounting holes. A range of loads were applied to the sample and a $1 \times 2 \mu \mathrm{m}^{2}$ area scanned ( $2 \mu \mathrm{m}$ in the fast scan direction) at a sliding speed of $2 \mu \mathrm{m} / \mathrm{s}$, whilst simultaneously recording the applied load, friction and the height of the cantilever. The results are shown in Figure 1, indicating a coefficient of friction of 0.27 for the nominally dry tested surface.

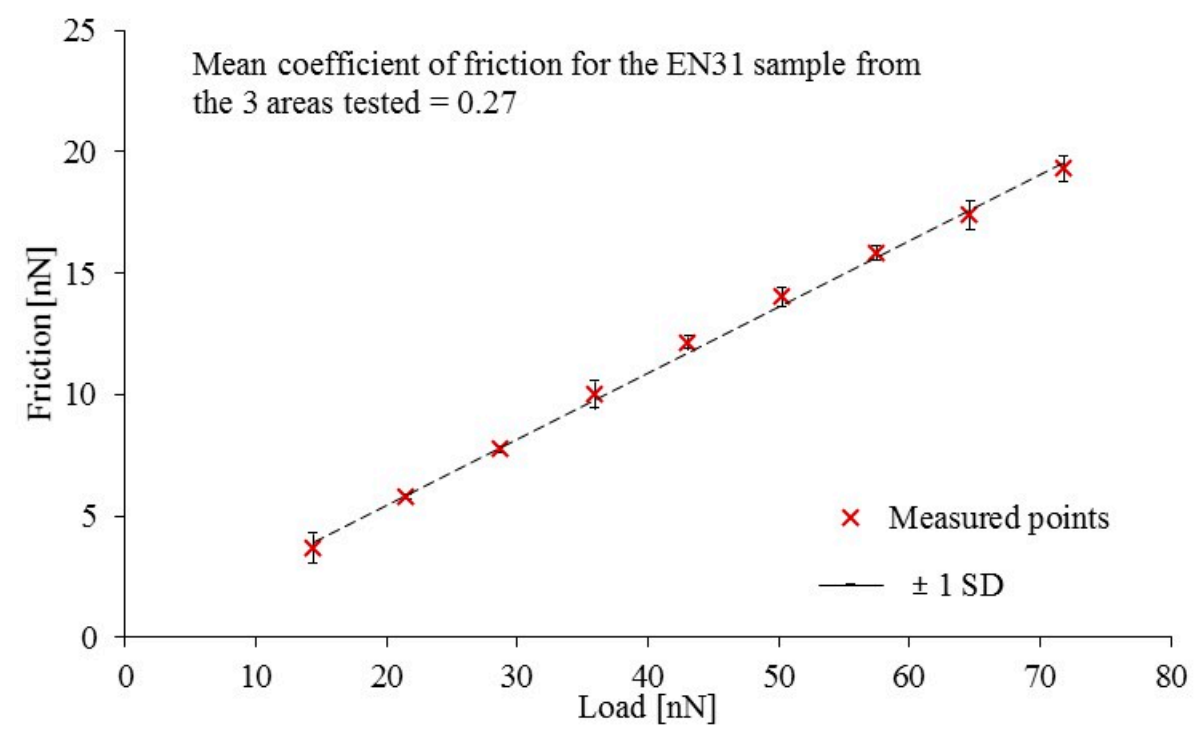

Figure 1. Measured frictional data from three areas scanned on the EN31 steel sample.

Figure 1 shows very good agreement between the results of the three tests, indicating that the procedure and sample surface topography are both repeatable and precisely controlled. The coefficient of friction is found as the gradient of the line and is in good agreement with similar tests on EN14 steel $[35,37]$. The contact is taken as nominally dry since the tests were conducted in a controlled atmosphere with $50 \pm 2 \%$ relative humidity resulting in a slight offset to the intercept, in agreement with water-surface condensation and meniscus growth models [38,39]. This is assumed to produce a constant offset to the friction trace, providing a small positive intercept to the graph in Figure 1, but insufficient to cause any hydrodynamic lift at the slow sliding speeds investigated.

To investigate the in-situ growth of the tribofilm, a tip load of $160 \mathrm{nN}$ was applied which produces a mean contact pressure of approximately $5 \mathrm{GPa}$. The scan rate was set at $29.6 \mathrm{~Hz}$ in order to allow 5000 full scans of a $1 \times 2 \mu \mathrm{m}^{2}(2 \mu \mathrm{m}$ in the fast scan direction) region over a period of $6 \mathrm{~h}$. These values are similar to those employed by Gosvami et al. [12] and have been shown to be sufficient for the formation of ZDDP-based tribofilms. These conditions result in a very high tip sliding speed of $118.4 \mu \mathrm{m} \cdot \mathrm{s}^{-1}$ which 
is found to result in non-Newtonian shear behaviour of the lubricant used in previous investigations [35].

The experimental procedure for additive activation is commenced by following the same calibration procedure described for the dry case, followed by measuring the surface in a nominally dry state. The initial measurements were made to ensure that measured friction was in line with the aforementioned initial dry testing condition and provide a baseline surface height. The lubricant was then injected into the contact while the tip was loaded against the surface, thereby restricting any drift. Sufficient lubricant was added to ensure that the generated meniscus was far removed from the scanning location. Continuous friction and height measurements were conducted for 5000 surface scans over a $6 \mathrm{~h}$ test duration. This procedure was repeated three times under the same scan conditions with a different tip and test area in each case. The bulk material and ambient temperatures during the testing was controlled to $20 \pm 0.5^{\circ} \mathrm{C}$.

\section{Experimental Results}

The results of three separate tests are provided in Figures 2 and 3, showing the cumulative tribofilm height relative to the initial scan and the evolution of coefficient of friction with time.

Figures $2-4$ show several distinct trends. Firstly, there is a clear initial drop in friction relative to the nominally dry contact measurement which is attributed to the reduction in adhesion through wetting of the contact under partial (mixed) regime of lubrication in line with that proposed by Bowden and Tabor [40], Tambe and Bhushan [41] and Chong and Rahnejat [42]. Secondly, following this initial drop relative to dry friction, there is a significant, but unstable further reduction in friction over the first $45 \mathrm{~min}$ of scanning. This coincides with an unstable film growth rate. Referring to Figures 2 and 3, for this region of variations an unstable film growth can be observed for tests 1 and 3, but not for test 2 where a steady reduction in friction with a steady film growth is observed. In the case of tests 1 and 3, an increase in friction is observed prior to a stable coefficient of friction being reached after $120 \mathrm{~min}$ of scanning. Test 2 displays a slower frictional response rate, also reaching a stable coefficient of friction after approximately $120 \mathrm{~min}$.

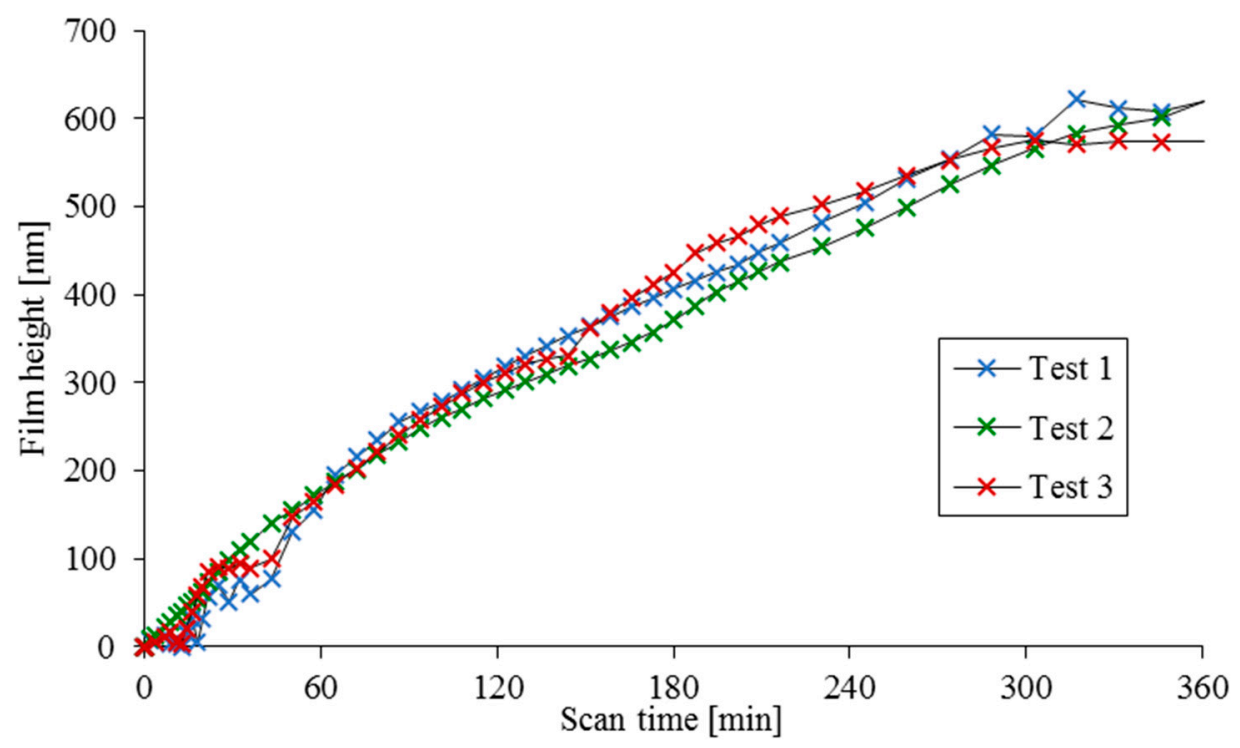

Figure 2. Measured surface height data from three scanned areas on the EN31 steel sample with the base oil containing MoDTC. 


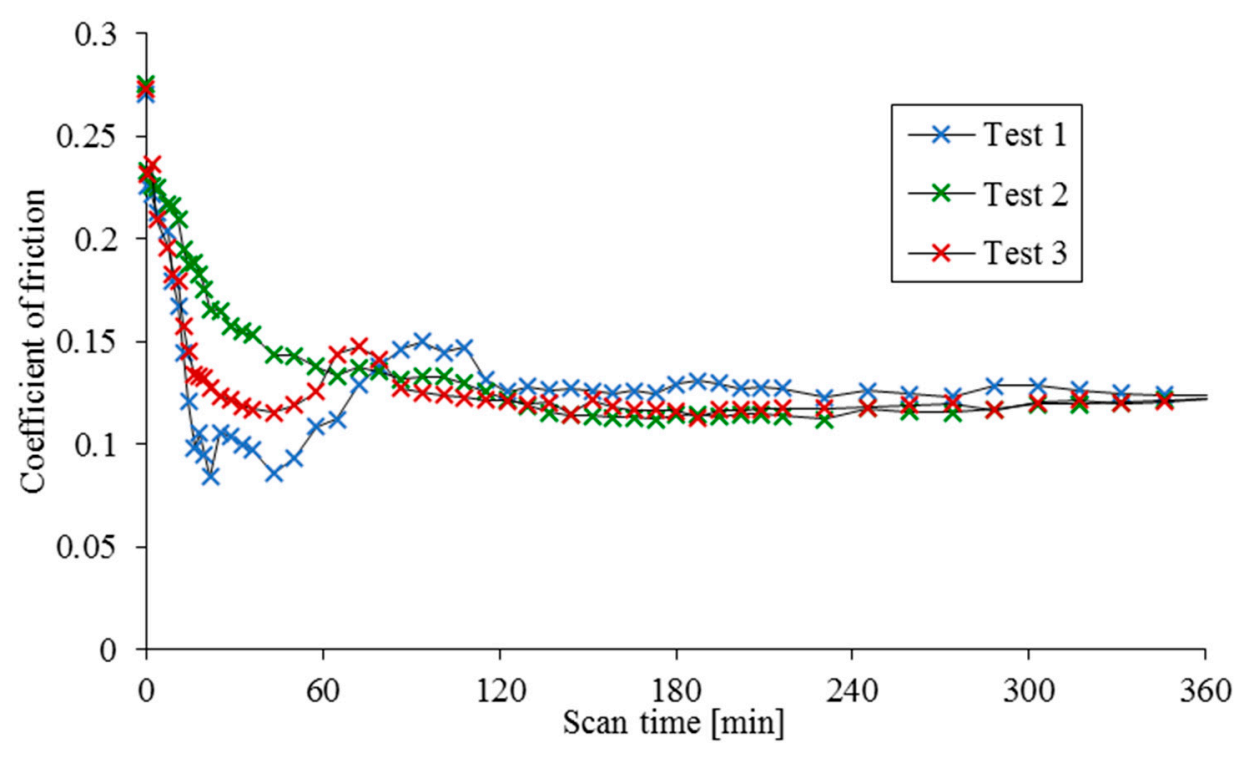

Figure 3. Measured coefficient of friction data from three scanned areas on the EN31 steel sample with base oil containing MoDTC.

An overlay of the mean measured coefficient of friction and the mean surface height for the three scans can be seen in Figure 4.

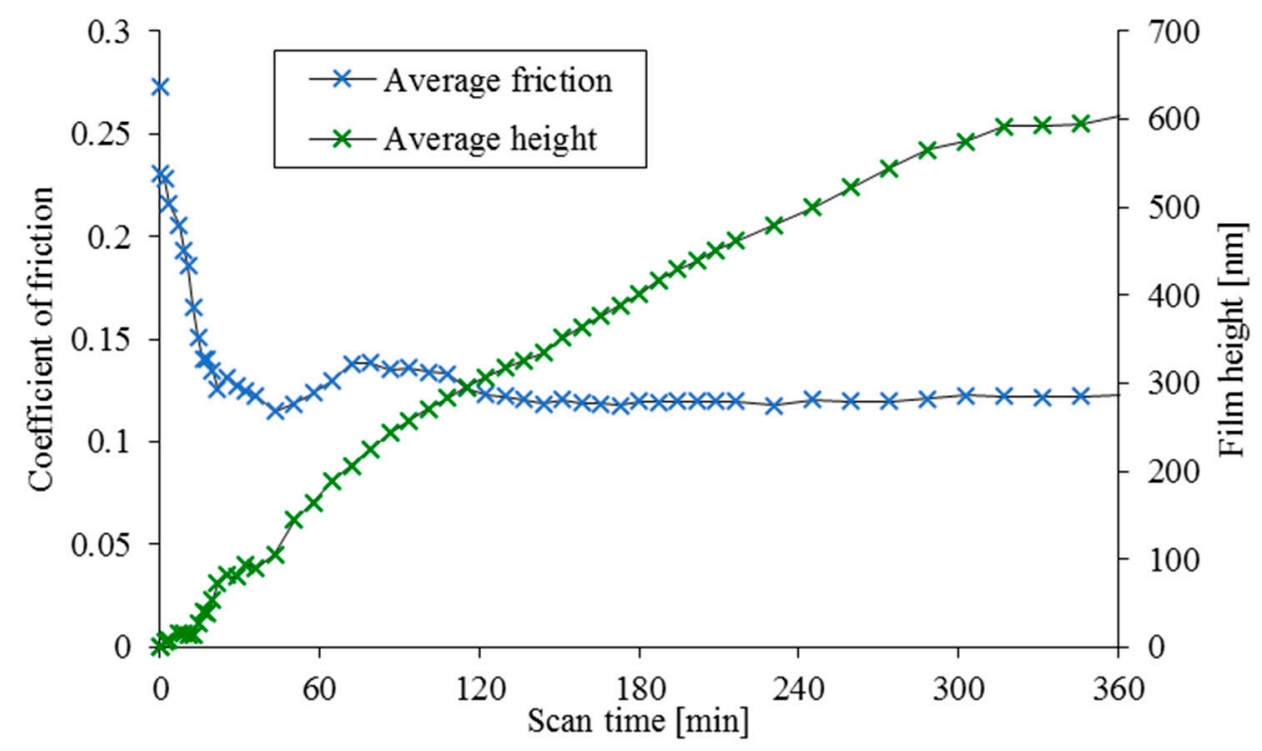

Figure 4. Mean coefficient of friction and mean surface height data from three scanned areas on the EN31 steel sample with base oil containing MoDTC.

Contrary to the evolving frictional characteristics, there is almost negligible change in the tribofilm height for the initial $30 \mathrm{~min}$ scanning duration, followed by an unsteady film growth for the next 30 min interval for tests 1 and 3, whilst in test 2 a slower, but smoother change in the growth of film height is observed. Finally, for all tests, the film growth stabilises after an hour and appears to plateau near the completion of test duration. The film growth in Figure 2, between approximately 120 and 300 min, appears to follow a near linear growth rate which is in agreement with the shear-promoted thermal activation model as the contact conditions and coefficient of friction remain almost unaltered. However, it is essential to modify the shear-induced thermal activation model in order to account for the reduced growth rate nearing the end of these tests and take into account the reduced film formation rate observed at the beginning of the tests, despite relatively high friction. 
Several studies have considered the wear of AFM tips through either scanning electron microscopy [43,44], or measurement of calibration samples [45] or even by measuring a nominally worn tip using a second fresh tip [29]. These techniques are not possible in the current study due to the application of the lubricant to the sample surface and the fragility of the components. The tip wear reported elsewhere has been rather slight and it is unclear what effects the lubricant and the formed tribofilm would have on the tip wear rate. Therefore, the tip wear is neglected in the current study.

\section{Discussion}

The stress-dependent film growth rate is predicted by the Arrhenius shear-promoted thermal activation model as:

$$
\Gamma_{\text {growth }}=\Gamma_{0} e^{-\frac{\Delta E_{a c t}-\Delta E_{m e c h}}{k_{B} T}}
$$

where $\Gamma_{\text {growth }}$ is the growth rate with the unit: $\mathrm{m}^{3} \mathrm{~s}^{-1}, \Gamma_{0}$ is referred to as the pre-exponential term, $\Delta E_{a c t}$ is the internal activation energy, given as the energy barrier in the absence of any applied stress, $k_{B}$ is the Boltzmann's constant $\left(1.38064852 \times 10^{-23} \mathrm{JK}^{-1}\right), T$ is the absolute temperature and $\Delta E_{\text {mech }}$ is the expended mechanical energy as:

$$
\Delta E_{\text {mech }}=\tau \Delta V
$$

where $\tau$ is the mean value of stress component affecting the activation barrier, in this case the contact shear stress and $\Delta V$ is the activation volume.

$$
\Gamma_{0}=v V_{m}
$$

where $v$ and $V_{m}$ are described by Gosvami et al. [12] as the attempt frequency (i.e., the rate of interactions between an additive molecule and the target surface) and the molar volume (the volume occupied by one mole of the growth species) respectively.

In the current application, $v$ and $V_{m}$ should be defined rather differently as the mechanical input energy is produced through shear rather than application of pressure. Therefore, the attempt frequency, $v$, becomes the number of molecules sheared by the AFM tip per second. This can be estimated by the area occupied by a single molecule on the surface, the footprint tip contact area and its sliding speed. The volume, $V_{m}$, is therefore no longer the molar volume, but the molecular volume (i.e., the volume of the product produced by the reaction of one molecule). $V_{m}$ is, therefore, regarded as the product of the area occupied by a molecule and the molecular-chain length.

Applying these definitions and the conditions of the experiment to the Arrhenius shear-promoted thermal activation model and adjusting for the best fit to the experimental data, yields the results shown in Figure 5. The best fit was found by applying the following conditions: $\Delta E_{a c t}=0.695 \mathrm{eV}, \Delta V=160 \times 10^{-30} \mathrm{~m}^{3}, v=1 \times 10^{15} \frac{1}{\mathrm{~s}}$ and $V_{m}=1.40 \times 10^{-27} \mathrm{~m}^{3}$.

However, as Figure 5 shows, the Arrhenius shear-promoted thermal activation model clearly does not predict a limiting value or any initial state of transience. Therefore, it is rather inadequate for the evaluation of full tribofilm forming characteristics. 


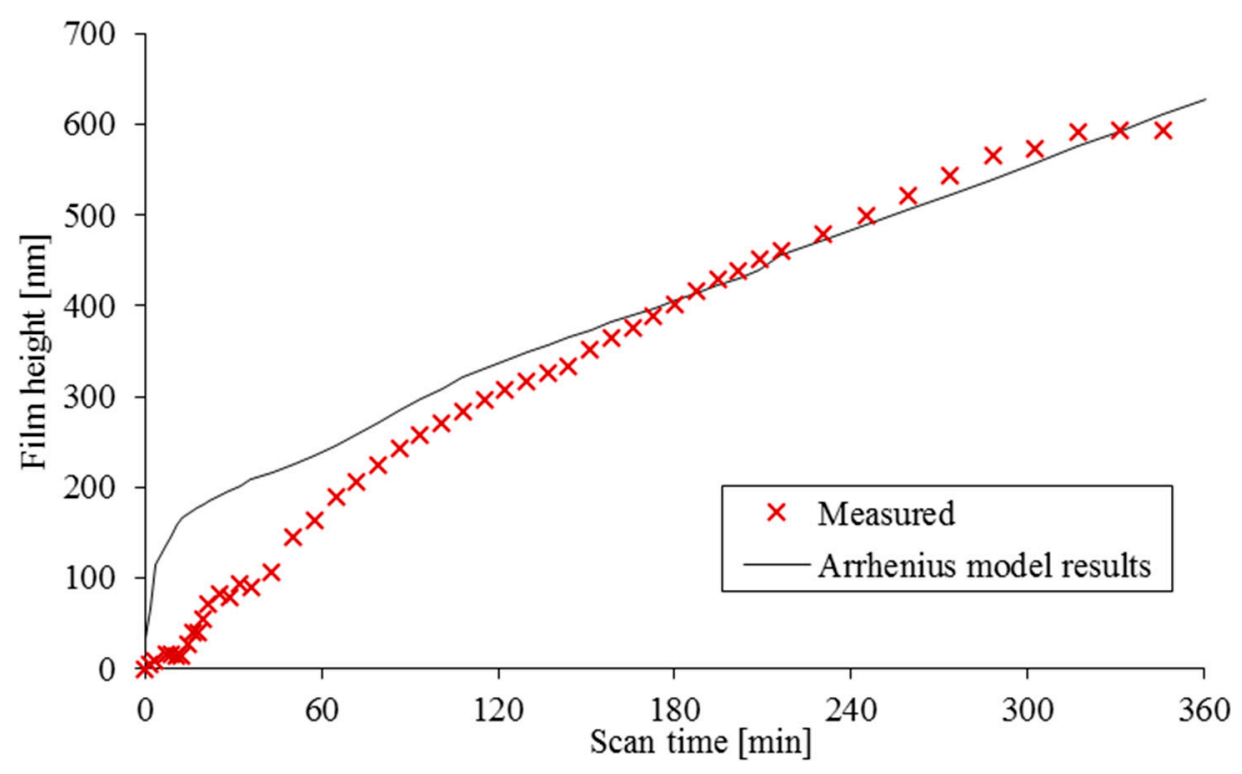

Figure 5. Comparison of the predictions of the Arrhenius shear promoted thermal activation model with the experimental measurements.

MoDTC and ZDDP are polar molecules and can adsorb to metallic surfaces through van der Waals interactions [3]. This provides for a high viscosity weakly adsorbed near surface layer [34], which can be considered as the mechanism for the initial stages of tribofilm formation, whereas there would not yet be a significant bond or performance benefit to the additive film formation in the case of MoDTC and ZDDP. This is thought to be the form an additive film takes through application of thermal energy alone. Gosvami et al. [12] showed that for ZDDP such a layer is formed to a depth of approximately $10 \mathrm{~nm}$ but was easily removed using the scanning conditions that were later shown to induce film growth.

From the state of an adsorbed layer, sufficient energy input is required to form a more permanent structure and a stronger bond to form with the target surface (a process commonly referred to as 'activation'). Adams et al. showed that, in UHV tribometry with a SFA, molecules bonded in a similar structure which can be sheared into activation [15]. This proposition is supported by the work of Zhang and Spikes [13], among others, at the microscale of tribometry. It is hypothesised that with adequate shear the polar attachment of the additives forms an anchor-point while the free ends are forced over and laid in the direction of shear [46]. Essentially, it is thought that the shearing action in combination with the available thermal energy would force the free ends of molecules into proximity with each other or with the solid surface, forming covalent bonds and thus promote the formation of a tribofilm.

The requirement for a molecule to be adsorbed to the surface prior to activation by the sliding tip provides a physical restriction to the chemical reaction rate predicted by the Arrhenius model. The finite coverage of molecules adsorbed to the surface should also be considered unless a large period of time is elapsed between successive scanning passes for a film covering the surface to stabilise. Therefore, the rate of adsorption must be taken into account in the modelling of the activation process.

Langmuir is credited with the first mathematical model for surface adsorption [47-49]. The Langmuir model considers the formation of an adsorbed monolayer onto a surface from a gas as a function of the adsorption, desorption rates and surface coverage through a simple expression as:

$$
\frac{d \theta}{d t}=K_{A}(1-\theta)-K_{D} \theta
$$

where $K_{A}$ is the rate of adsorption, $K_{D}$ is the rate of desorption, $\theta$ is the fraction of the area covered by a deposited layer and $t$ is time. 
A Langmuir adsorption model has been applied previously to the case of lubricant additive film formation by Dacre and Bovington [50,51]. They investigated the effect of concentration, temperature and stirring on the adsorption of ZDDP on steel and determined values of $K_{A}$ and $K_{D}$ for a range of cases.

Although the Langmuir model allows for a limiting growth rate at the onset of the scanning process, it does not provide an explanation for the limiting growth observed at the culmination of the experiments. A possible reason for the reduction in the growth rate and for the initial transience is provided through inclusion of a multi-molecular layer adsorption model. The first multi-molecular layer adsorption model was provided by Brunauer, Emmett and Teller [52] and have since been named after them as the so-called BET model. Under the proposed conditions, additive molecules would have the ability to adsorb in layers upon each other in the form of a stack. Desorption can also occur at all points within the stack such that a steady state condition is always reached with a finite number of layers. Under these conditions the shear experienced by each molecule at each adsorption site may be considered as inversely proportional to the number of molecular layers resident there $[53,54]$.

A BET multi-molecular layer adsorption model can be applied and solved analytically for a finite maximum number of layers. For the current case, an initial condition at which there would be no adsorbent coverage on the surface was applied. In the time between successive passes of the AFM tip, the growth on any layer $x$ can be described as:

$$
\theta_{n, x}=\theta_{n-1, x}+\int_{n-1}^{n} \theta_{x-1} K_{A x}\left(1-\theta_{x}\right)-\theta_{x} \sum_{i=x}^{1} K_{D i} d t
$$

where $n$ denotes the descrete time step, $\sum_{i=x}^{1} K_{D i}$ accounts for the probability that any molecule in the stack can desorb to reduce the coverage at layer $x$ and the growth rate would be limited by the fraction coverage of the layer $x-1$, multiplying through by $\theta_{x-1}[55]$.

Applying the multi-molecular layer adsorption model to the Arrhenius equation yields:

$$
\Gamma_{\text {growth }}=\sum_{x=1}^{x_{\max }}\left(\theta_{t, x}-\theta_{t, x+1}\right) v V_{m} e^{-\frac{\Delta E_{a c t}-\frac{\tau_{e}}{x} \Delta V}{k_{B} T}}
$$

where $x_{\max }$ is the maximum number of molecules in a stack accounted for in the simulation study.

Equation (6) shows that the effective shear stress term in the mechanical energy is reduced as the number of adsorbed layers increases. The surface monolayer adsorption and the shear-promoted thermal activation can therefore be modelled as a symbiotic loop in which molecules adsorb over a given period of time, with a scanning pass activating some proportion of these. Therefore, a new surface coverage is determined, and adsorption is allowed over the next time period before another scanning pass occurs.

Another factor that should be considered concerns the removal of the adhered molecules which are unsuccessful in the bonding reaction. If the expended shear energy is sufficient, these molecules may be removed from the surface and return to their dissolved state in the bulk oil. As the desorption rate is energy dependent, it would be logical to relate the desorption rate to the generated thermal and mechanical energies, while only using the former for desorption occurring outside the contact domain. As a result, a process may be conceived as illustrated in Figure 6. A similar process was described by Heuberger et al. [56] for the tribochemical film formation of ZDDP using MTM. 


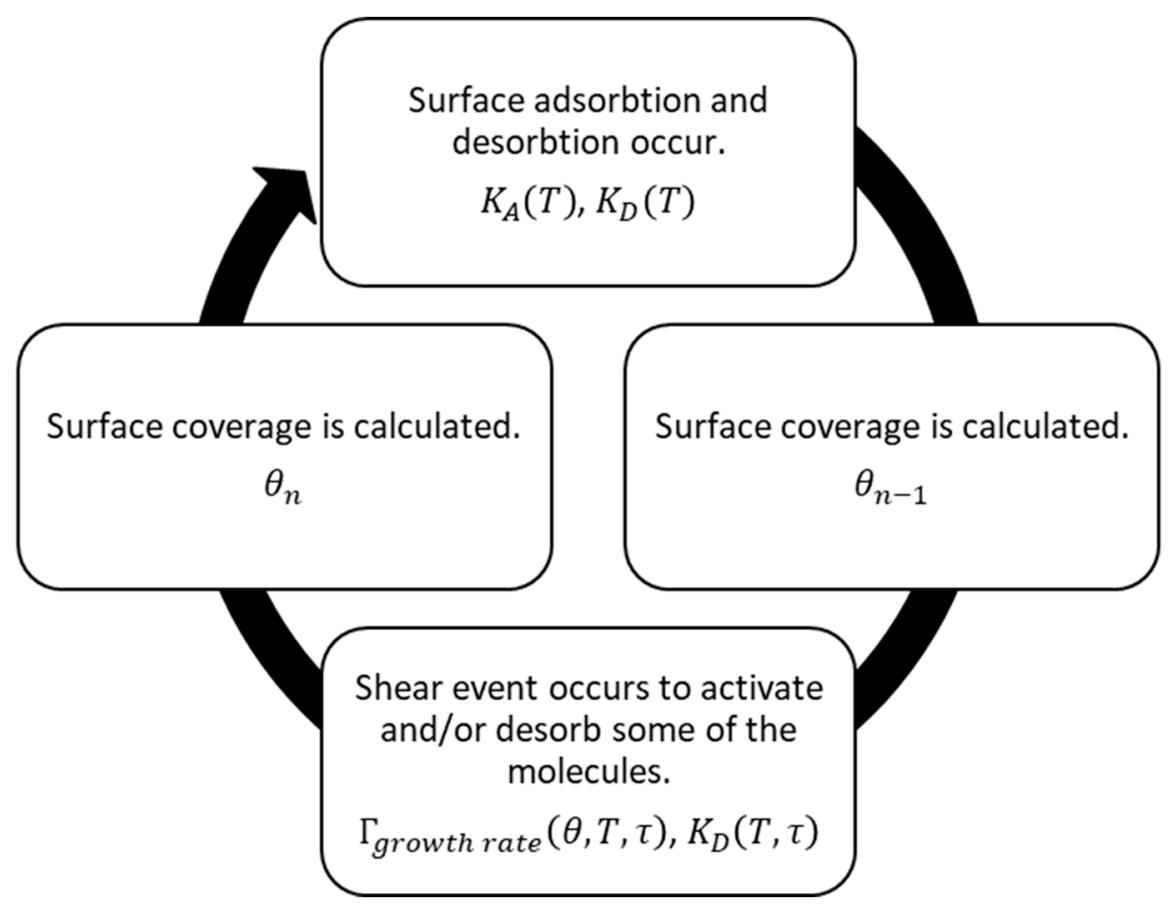

Figure 6. Cyclic process illustrating adsorption and activation of additives by a cyclic tribological event.

Applying the multi-molecular layer model yields the results shown in Figure 7, where the average depth of the adsorbed film is added to the activated tribofilm height predicted by the Arrhenius equation. An estimated layer height of $2.4 \mathrm{~nm}$ has been applied here as this has been reported as the mean molecular length of free ZDDP molecules determined by Georges et al. [57] using dynamic light scattering.

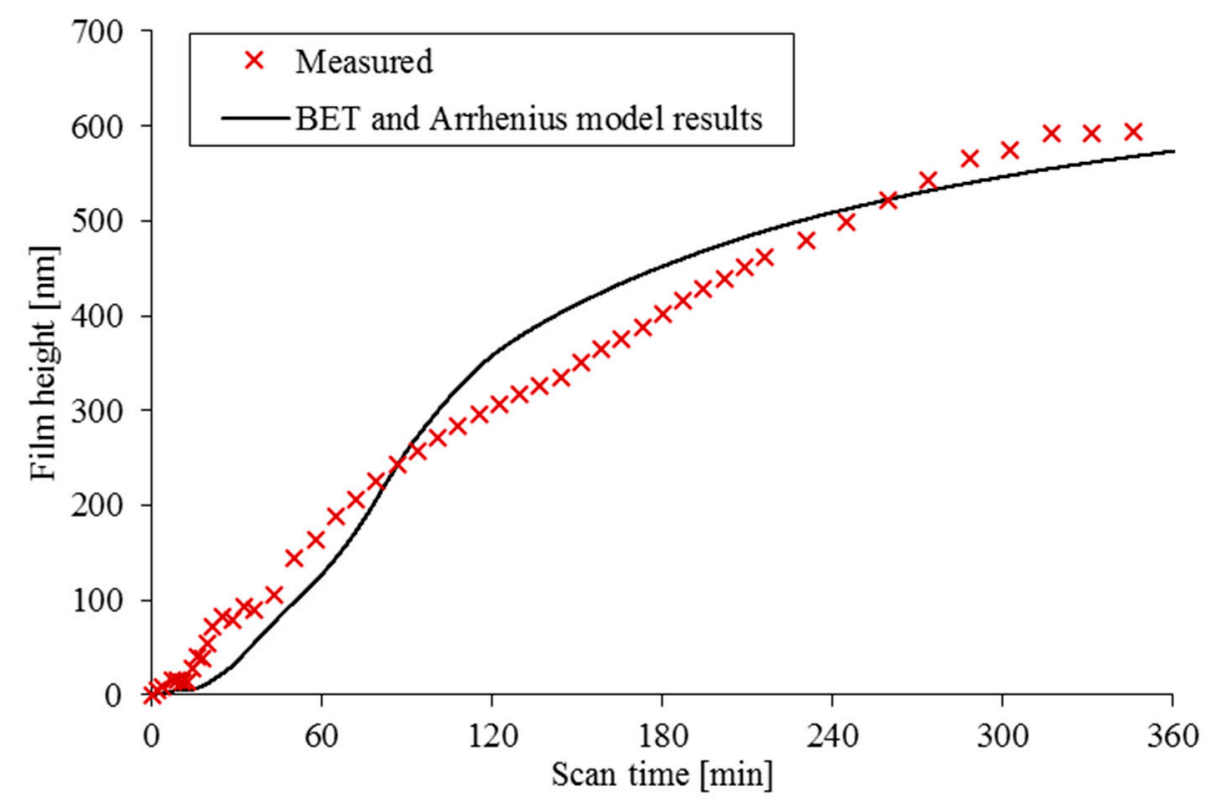

Figure 7. Growth of tribofilm height with time as measured and modelled using the BET adsorption model paired with the Arrhenius shear-promoted thermal activation model.

Figure 8 shows the predicted fraction of the surface covered with bonded molecules 1 , 2, 3, 4 and 5 layers deep within the test period. It can be seen that the mono-layer coverage reduces after $60 \mathrm{~min}$ as it becomes increasingly covered with further molecular layers. 


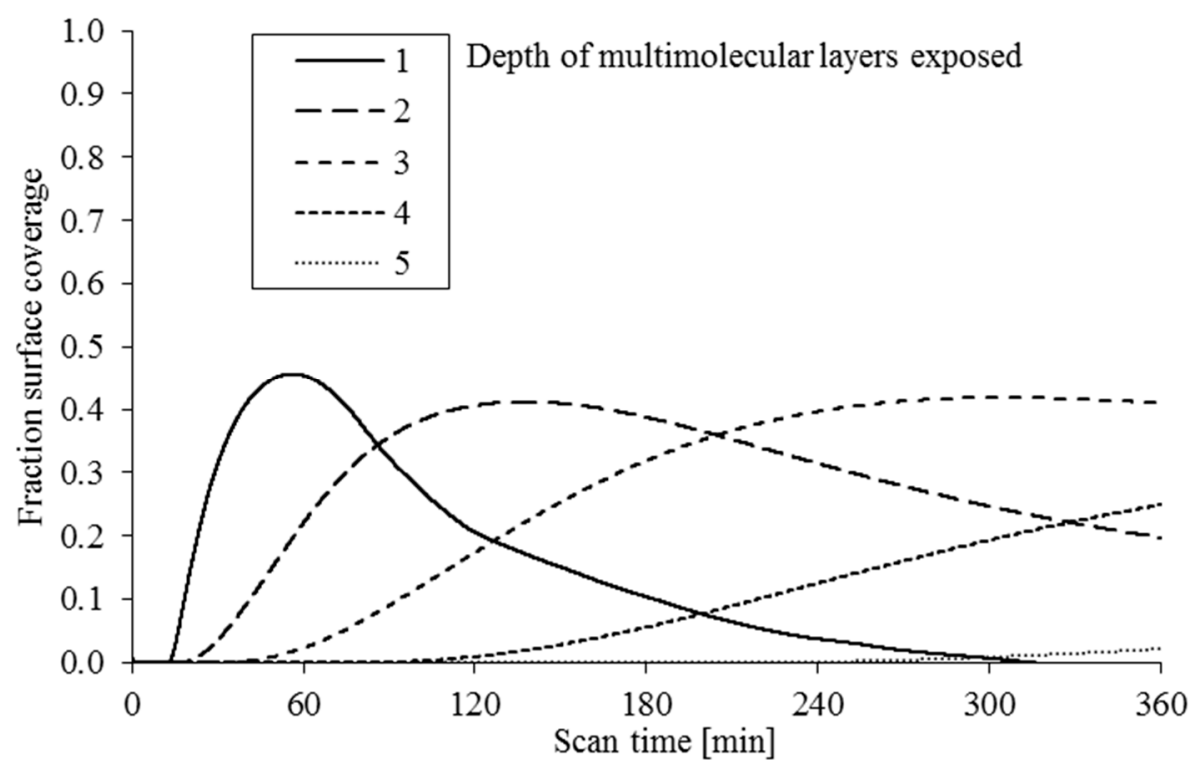

Figure 8. The predicted fraction of the surface coverage of multi-molecular layers within the test period.

Figure 9 shows that the total predicted surface coverage stabilises at $85 \%$ of the surface after $180 \mathrm{~min}$, although there remains slight fluctuation due to changes in shear stress and activation rate.

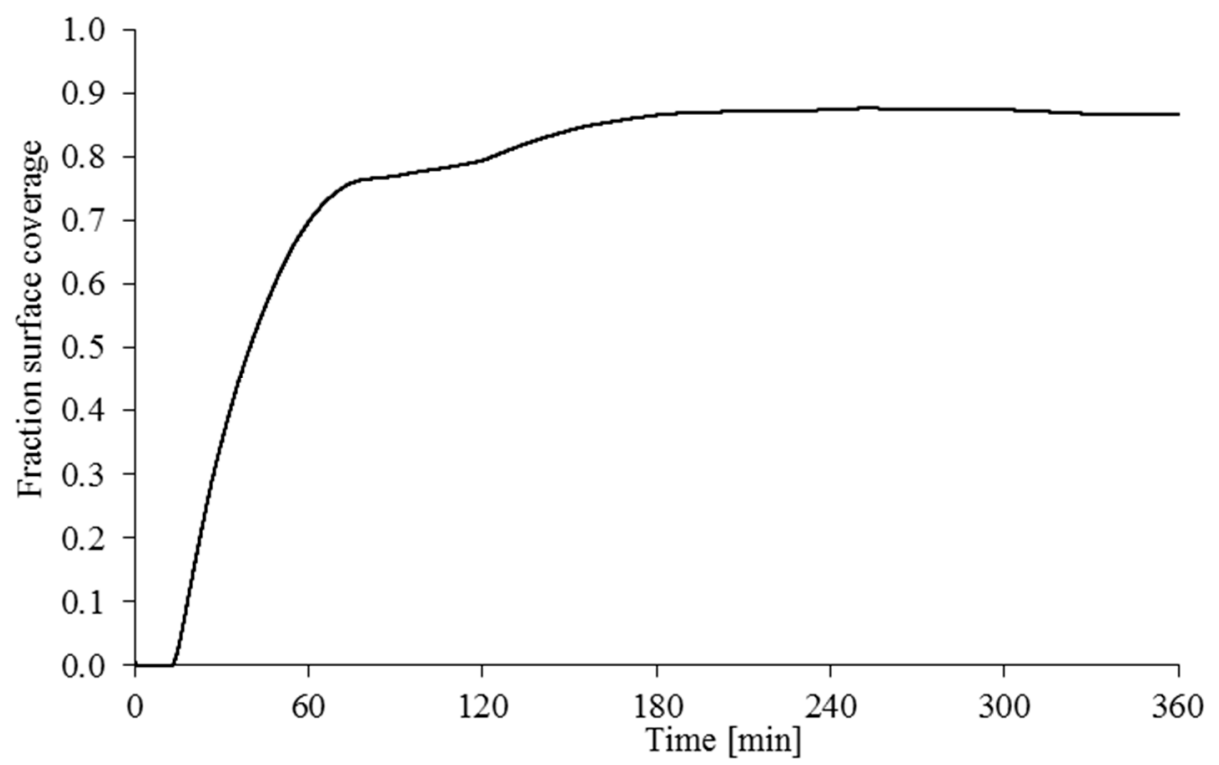

Figure 9. Total predicted fraction of substrate surface coverage in the test period.

Referring back to Figure 7, it is shown that the multi-molecular layer adsorption model not only provides a reduced initial growth rate in comparison with the use of the Arrhenius model alone (Figure 5), but also provides an explanation for the reducing film growth at the end of the test period. With additional testing for further understanding of the adsorption and desorption rates for each of the multi-molecular layers, it is expected that even better conformance of predictions to the measured data may be achieved.

In micro-scale contacts, some change would have to be made to the cyclic process shown in Figure 6 as the adsorbed multi-molecular layers, predicted through BET, may be sheared-off under the contact conditions, particularly in asperity-pair ploughing. The unusual case of the AFM scanning probe removes this issue in the current investigation as 
the fixed end of the cantilever holding the tip is a reactive loading system, which adjusts the tip height in order to maintain a constant load over varying topography. This is of course, not the case in micro-scale contacts.

Figures 7 and 8 show that the rate of growth of the tribofilm predicted through the new combined BET and Arrhenius model begins to fall as the adsorbed film tends to an average depth of 3 molecules. This can be seen to occur even though there is ample adsorbed film coverage as shown in Figure 9.

The inclusion of an adsorption model in the prediction of tribofilm growth offers an opportunity for the development of competitive/antagonistic additive technology, where boundary active additives compete for adsorption sites. It has been observed that certain additive combinations provide harmonic/synergistic or disruptive/antagonistic relationships. In the case of MoDTC and ZDDP, it has been noted that there is a harmonic/synergistic relationship in automotive lubricant applications where low shear strength $\mathrm{MoS}_{2}$ layers form within the ZDDP-based tribofilm, offering a slip plane which reduces friction, whilst ZDDP offers exceptional wear protection $[34,58]$. However, if the ratio of adsorption rates between the ZDDP and MoDTC are altered, then the ratio of the tribofilm composition can be tailored accordingly. MoDTC is one of several lubricant-soluble polar molecules capable of producing a $\mathrm{MoS}_{2}$ tribofilm. Therefore, it may be possible to make a selection based on the predicted performance by the expounded model. Alternatively, detergents such as calcium sulfonate have been shown to disrupt the growth of ZDDP, leading to essential compromises in lubricant formulation [59,60]. These relationships are well-suited for predictions with a competitive adsorption model as they allow a limited number of surface sites to be accounted for prior to the additive activation event. As a result, it is possible to determine a fractional content of subsequent layers in combined MoDTC and ZDDP competition and the growth of ZDDP in competition with a detergent molecule as well as other surfactant combinations.

Ostwald and de Izaguirre [61] developed an early competitive adsorption model, based on the work of Freundlich [62] and a similar model also exists for Langmuir-based adsorption [63].

Similarly, the current approach allows for discrepancies between additives' performances observed for different surface materials or coatings. In a typical fully formulated lubricant, there are many species competing for bonding/adsorbing to a finite number of surface sites, and variation in the surface forces is likely to cause significant differences in tribofilm growth and subsequent lubricant system performance in mixed and boundary regimes of lubrication. The analytical model proposed shows reasonable correlation to the test results in Figure 7. However, the average results were generated from a limited number of tests supported by observed trends [12].

\section{Concluding Remarks}

The paper presents a novel method for simultaneous in situ measurement and characterisation of tribofilms through use of AFM in lateral force mode. Crucially, this new method allows for direct measurement of the generated tribofilm height as well as the resistive shear force, which is an essential variable for accurate application of the Arrhenius model to tribochemistry. In addition, a new predictive method is presented which combines mechanical, physical and chemical processes in a multi-step model, accounting for many of the observed and, not hitherto satisfactorily explained, phenomena in complex tribodynamic systems.

The proposed analytical model allows the full lubricant-surface-additive system to be evaluated in a transient manner. Through the potential extensions already outlined, it is possible to account for complex lubricant formulations and generated tribofilms through processes such as antagonistic/competitive adsorption.

Author Contributions: Conceptualization: all, methodology: M.L., Software, M.L.; Validation, M.L., Experimentation: M.L., investigation, M.L., Interpretation: All, formal analysis: M.L., data curation: 
M.L., original drafting: M.L. and N.M., review and editing: All, Visualization, M.L. Supervision: N.M. and H.R. All authors have read and agreed to the published version of the manuscript.

Funding: This research was funded by the Engineering and Physical Sciences Research Council (EPSRC), Grant Number EP/G012334/1, UK.

Acknowledgments: The authors would like to express their gratitude to the Engineering and Physical Sciences Research Council (EPSRC) for funding of this research under the Program Grant Encyclopaedic.

Conflicts of Interest: Authors claim no conflict of interest.

\section{Nomenclature}

$\begin{array}{ll}k_{A} & \text { Rate of adsorption } \\ k_{B} & \text { Boltzmann's constant } \\ k_{D} & \text { Rate of desorption } \\ t & \text { Time } \\ T & \text { Absolute temperature } \\ v & \text { Rate of interactions of molecules with target surface atoms } \\ V_{m} & \text { Molar volume } \\ \text { Greek Symbols: } & \\ \Delta E_{\text {act }} & \text { Internal activation energy } \\ \Delta E_{\text {mech }} & \text { Mechanical applied energy } \\ \theta & \text { Fraction area of deposited layer } \\ \Gamma_{0} & \text { Pre-exponential term in the Arrhenius Equation } \\ \Gamma_{\text {growth }} & \text { Rate of growth } \\ \tau & \text { Mean barrier stress }\end{array}$

\section{References}

1. Holmberg, K.; Erdemir, A. Influence of tribology on global energy consumption, costs and emissions. Friction 2017, 5, $263-284$. [CrossRef]

2. Stachowiak, G.; Batchelor, A. Lubricants and Their Composition. In Engineering Tribology, 4th ed.; Butterworth-Heinemann: Oxford, UK, 2013; pp. 51-104.

3. Mortier, R.; Orszulik, S. Chemistry and Technology of Lubricants, 2nd ed.; Blackie Academic and Professional: London, UK, 1997.

4. Bec, S.; Tonck, A.; Georges, J.; Roper, G. Synergistic effects of MoDTC adn ZDDP on frictional behaviour of tribofilms at the nanometer scale. Tribol. Lett. 2004, 17, 797-809. [CrossRef]

5. Risdon, T.; Gresty, D. An Historical Review of Reductions in Fuel Consumption of United States and European Engines with MoS2; Pap. No. 750674; SAE Technical Paper: Warrendale, PA, USA, 1975; pp. 1-12.

6. Spikes, H. Friction Modifier Additives. Tribol. Lett. 2015, 60, 1-26. [CrossRef]

7. Laidler, K. The Development of the Arrhenius Equation. J. Chem. Educ. 1984, 61, 494-498. [CrossRef]

8. Prandtl, L. A conceptual model to the kinetic theory of solid bodies. ZAMM J. Appl. Math. Mech. Z. Angew. Math. Mech. 1928, 8, 85-106. [CrossRef]

9. Eyring, H. Viscosity, plasticity and diffusion as examples of absolute reaction rates. J. Chem. Phys. 1936, 4, 283-291. [CrossRef]

10. Tysoe, W. On stress induced tribochemical reaction rates. Tribol. Lett. 2017, 65, 1-16. [CrossRef]

11. Spikes, H. Stress-augmented thermal activation: Tribology feels the force. Friction 2018, 6, 1-31. [CrossRef]

12. Gosvami, N.; Bares, J.; Mangolini, F.; Konicek, A.; Yablon, D.; Carpick, R. Mechanisms of antiwear tribofilm growth revealed in situ by single-asperity sliding contacts. Science 2015, 348, 102-106. [CrossRef]

13. Zhang, J.; Spikes, H. On the mechanisum of ZDDP antiwear film formation. Tribol. Lett. 2016, 63, 1-15. [CrossRef]

14. Eyring, H.; Polanyi, M. On simple gas reactions. Z. Phys. Chem. 2013, 227, 1221-1245. [CrossRef]

15. Adams, H.; Miller, B.; Furlong, O.; Fantauzzi, M.; Navarra, G.; Rossi, A.; Xu, Y.; Kotvis, P.; Tysoe, W. Modeling Mechanochemical Reaction Mechanisms. Am. Soc. Chem. Appl. Mater. Interfaces 2017, 9, 26531-26538. [CrossRef]

16. Akhmatov, A. Molecular Physics of Boundary Friction, 1st ed.; Translated from Russian by Kaner, N; Israel Program for Scientific Translations: Jerusalem, Israel, 1963.

17. Hirst, W.; Moore, A. Elastohydrodynamic lubrication at high pressures II. Non-Newtonian behaviour. Proc. R. Soc. A: Math. Phys. Eng. Sci. 1979, 365, 537-565.

18. Felts, J.; Oyer, A.; Hernández, S.; Whitener, K.; Robinson, J.; Walton, S.; Sheehan, P. Direct mechanochemical cleavage of functional groups from graphene. Nature Commun. 2015, 6, 1-7. [CrossRef] [PubMed]

19. Ewen, J.; Gattinon, C.; Morgan, N.; Spikes, H.; Dini, D. Nonequilibrium Molecular Dynamics Simulations of Organic Friction Modifiers Adsorbed on Iron Oxide Surfaces. Langmuir 2016, 32, 4450-4463. [CrossRef] 
20. Yeon, J.; He, X.; Martini, A.; Kim, S. Mechanochemistry at Solid Surfaces: Polymerization of Adsorbed Molecules by Mechanical Shear at Tribological Interfaces. Appl. Mater. Interfaces 2017, 9, 3142-3148. [CrossRef]

21. Naveira-Suarez, A. The Behaviour of Antiwear Additives in Lubricated Rolling-Sliding Contacts. Ph.D. Thesis, Luleå University of Technology, Luleå, Sweden, 2011.

22. Naveira-Suarez, A.; Tomala, A.; Grahn, M.; Zaccheddu, M.; Pasaribu, R.; Larsson, R. The influence of base oil polarity and slide-roll ratio on additive-derived reaction layer formation. Proc. IMechE Part J Eng. Tribol. 2011, 225, 565-576. [CrossRef]

23. Ratoi, M.; Niste, V.; Alghawel, H.; Suen, Y.; Nelson, K. The impact of organic friction modifiers on engine oil tribofilms. Royal Soc. Chem. 2014, 4, 4278-4285. [CrossRef]

24. Ghanbarzadeh, A.; Parsaeian, P.; Morina, A.; Wilson, M.; van Eijk, M.; Nedelcu, I.; Dowson, D.; Neville, A. A Semi-deterministic Wear Model Considering the Effect of Zinc Dialkyl Dithiophosphate Tribofilm. Tribol. Lett. 2016, 61, 1-15. [CrossRef]

25. Fujita, H.; Spikes, H. The formation of zinc dithiophosphate antiwear films. Proc. IMechE Part J. Eng. Tribol. 2004, 218, 265-277. [CrossRef]

26. Shimizu, Y.; Spikes, H. The Influence of Slide-Roll Ratio on ZDDP Tribofilm Formation. Tribol. Lett. 2016, 64, 1-11. [CrossRef]

27. Stratmanna, A.; Jacobsa, G.; Hsub, C.; Gachotc, C.; Burghardt, G. Antiwear tribofilm growth in rolling bearings under boundary lubrication conditions. Tribol. Int. 2017, 113, 43-49. [CrossRef]

28. Akchurin, A.; Bosman, R. A deterministic stress-activated model for tribo-film growth and wear simulation. Tribol. Lett. 2017, 65, 1-9. [CrossRef]

29. Khurshudov, A.; Kato, K.; Koide, H. Nano-wear of the diamond AFM probing tip under scratching of silicon, studied by AFM. Tribol. Lett. 1996, 2, 345-354.

30. Tao, Z.; Bhushan, B. Surface modification of AFM silicon probes for adhesion and wear reduction. Tribol. Lett. 2006, 21, 1-16. [CrossRef]

31. Jacobs, T.; Gotsmann, B.; Lantz, M.; Carpick, R. On the Application of Transition State Theory to Atomic-Scale Wear. Tribol. Lett. 2010, 39, 257-271. [CrossRef]

32. Archard, J. Contact and Rubbing of Flat Surfaces. J. Appl. Phys. 1953, 24, 981-988. [CrossRef]

33. Parenago, O.; Vipper, A.; Kuz'mina, G. Zinc and molybdenum dithiocarbamates-Antioxidant additives. Lubr. Sci. 2001, 13, 113-124. [CrossRef]

34. Morina, A.; Neville, A. Tribofilms: Aspects of formation, stability and removal. J. Phys. D Appl. Phys. 2007, 40, 5476-5487. [CrossRef]

35. Leighton, M.; Nicholls, T.; De La Cruz, M.; Rahmani, R.; Rahnejat, H. Combined lubricant-surface system perspective: Multi-scale numerical-experimental investigation. Proc. IMechE Part J. J. Eng. Tribol. 2017, 231, 910-924. [CrossRef]

36. Buenviaje, C.; Ge, S.; Rafaillovich, M. Atomic force microscopy calibration methods for lateral force, elasticity, and viscosity. MRS Online Proc. Libr. 1998, 522, 187-192. [CrossRef]

37. Umer, J.; Morris, N.; Leighton, M.; Rahmani, R.; Howell-Smith, S.; Wild, R.; Rahnejat, H. Asperity level tribological investigation of automotive bore material. Tribol. Int. 2018, 117, 131-140. [CrossRef]

38. Riedo, E.; Lévy, F.; Brune, H. Kinetics of capillary condensation in nanoscopic sliding friction. Phys. Rev. Lett. 2002, 88, 185505. [CrossRef]

39. Teodorescu, M.; Rahnejat, H. Dry and wet nano-scale impact dynamics of rough surfaces with or without a self-assembled monolayer. Proc. IMechE Part N J. Nanoeng. Nanosyst. 2007, 221, 49-58. [CrossRef]

40. Bowden, F.; Tabor, D. The Friction and Lubrication of Solids, 2nd ed.; Oxford University Press: New York, NY, USA, 1950.

41. Tambe, N.; Bhushan, B. Nanowear mapping: A novel atomic force microscopy based approach for studying nanoscale wear at high sliding velocities. Tribol. Lett. 2005, 20, 83-90. [CrossRef]

42. Chong, W.W.F.; Rahnejat, H. Nanoscale friction as a function of activation energies. Surf. Topogr. Metrol. Prop. 2015, 3, 044002. [CrossRef]

43. Killgore, J.; Geiss, R.; Hurley, D. Continuous Measurement of Atomic Force Microscope Tip Wear by Contact Resonance Force Microscopy. Small 2011, 7, 1018-1022. [CrossRef] [PubMed]

44. Bloo, M.; Haitjema, H.; Pril, W. Deformation and wear of pyramidal, silicon-nitride AFM tips scanning micrometre-size features in contact mode. Measurement 1999, 25, 203-211. [CrossRef]

45. Maw, W.; Stevens, F.; Langford, S.; Dickinson, J. Single asperity tribochemical wear of silicon nitride studied by atomic force microscopy. J. Appl. Phys. 2002, 92, 5103-5509. [CrossRef]

46. Adams, H.; Garvey, M.; Ramasamy, U.; Ye, Z.; Martini, A.; Tysoe, W. Shear-Induced Mechanochemistry: Pushing Molecules Around. J. Phys. Chem. 2015, 119, 7115-7123. [CrossRef]

47. Langmuir, I. The constitution and fundamental properties of solids and liquids. Part I: Solids. J. Am. Chem. Soc. 1916, 38, 2221-2295. [CrossRef]

48. Langmuir, I. The constitution and fundamental properties of solids and liquids. Part II: Liquids. J. Am. Chem. Soc. 1917, 39, 1848-1906. [CrossRef]

49. Langmuir, I. The adsorption of gases on plane surfaces of glass, mica and platinum. J. Am. Chem. Soc. 1918, 40, 1361-1403. [CrossRef]

50. Dacre, B.; Bovington, C. The adsorption and desorption of Zinc di-isopropyldithiophosphate on steel. Trans. ASLE 1982, 25, 546-554. [CrossRef] 
51. Bovington, C.; Dacre, B. The Adsorption and Reaction of Decomposition Products of Zinc Di-Isopropyldiophosphate on Steel. Trans. ASLE 1984, 27, 252-258. [CrossRef]

52. Brunauer, S.; Emmett, P.; Teller, E. Adsorption of gases in multimolecular layers. J. Am. Chem. Soc. 1938, 60, 309-319. [CrossRef]

53. Mantell, C. Adsorption, 2nd ed.; McGraw-Hill Book Company: New York, NY, USA, 1951.

54. Clarke, A. The Theory of Adsorption and Catalysis, 1st ed.; Academic Press: New York, NY, USA, 1970.

55. Ruthven, D. Principles of Adsorption and Adsorption Processes, 1st ed.; Wiley-Inderscience: New York, NY, USA, 1984.

56. Heuberger, R.; Rossi, A.; Spencer, N. Pressure Dependence of ZnDTP Tribochemical Film Formation: A Combinatorial Approach. Tribol. Lett. 2007, 28, 209-222. [CrossRef]

57. Georges, J.M.; Tonck, A.; Poletti, S.; Yamaguchi, E.S.; Ryason, P.R. Film thickness and mechanical properties of adsorbed neutral and basic zinc disobutyl dithiophosphates. Tribol. Trans. 1998, 41, 543-553. [CrossRef]

58. de Barros'Bouchet, M.; Martin, J.; Le-Mogne, Y.; Vacher, B. Boundary lubrication mechanisms of carbon coatings by MoDTC and ZDDP additives. Tribol. Int. 2005, 38, 257-264. [CrossRef]

59. Kapsa, P.; Martin, J.; Blanc, C.; Georges, J. Antiwear Mechanisum of ZDDP in the Presence of Calcium Sulfonate. Trans. ASME J. Lubr. Technol. 1981, 103, 486-494. [CrossRef]

60. Greenall, A.; Neville, A.; Morina, A.; Sutton, M. Investigation of the interactions between a novel, organic anti-wear additive, ZDDP and over based calcium sulphonate. Tribol. Int. 2012, 46, 52-61. [CrossRef]

61. Ostwald, W.; de Izaguirre, R. Ueber eine allgemeinere Theorie der Adsorption von Lösungen. Kolloid-Zeitschrift 1922, 30, 279-306. [CrossRef]

62. Freundlich, H. Of the adsorption of gases. Section II. Kinetics and energies of gas adsorption. Trans. Faraday Soc. 1932, 28, 195-201. [CrossRef]

63. Kipling, J.; Tester, D. Adsorption from binary mixtures of non-electrolytes. Nature 1951, 167, 612. [CrossRef] [PubMed] 